\title{
Crystal structure of the Yersinia enterocolitica type III secretion chaperone SycD in complex with a peptide of the minor translocator YopD
}

Madeleine Schreiner and Hartmut H Niemann*

\begin{abstract}
Background: Type III secretion systems are used by Gram-negative bacteria as "macromolecular syringes" to inject effector proteins into eukaryotic cells. Two hydrophobic proteins called translocators form the necessary pore in the host cell membrane. Both translocators depend on binding to a single chaperone in the bacterial cytoplasm to ensure their stability and efficient transport through the secretion needle. It was suggested that the conserved chaperones bind the more divergent translocators via a hexapeptide motif that is found in both translocators and conserved between species.

Results: We crystallized a synthetic decapeptide from the Yersinia enterocolitica minor type III secretion translocator YopD bound to its cognate chaperone SycD and determined the complex structure at $2.5 \AA$ resolution. The structure of peptide-bound SycD is almost identical to that of apo SycD with an all helical fold consisting of three tetratricopeptide repeats (TPRs) and an additional C-terminal helix. Peptide-bound SycD formed a kinked head-tohead dimer that had previously been observed for the apo form of SycD. The homodimer interface comprises both helices of the first tetratricopeptide repeat. The YopD peptide bound in extended conformation into a mainly hydrophobic groove on the concave side of SycD. TPRs 1 and 2 of SycD form three hydrophobic pockets that accommodated the conserved hydrophobic residues at position 1, 3 and 6 of the translocator hexapeptide sequence. Two tyrosines that are highly conserved among translocator chaperones contribute to the hydrophobic patches but also form hydrogen bonds to the peptide backbone.

Conclusions: The interaction between SycD and YopD is very similar to the binding of the Pseudomonas minor translocator PopD to its chaperone PcrH and the Shigella major translocator IpaB to its chaperone IpgC. This confirms the prediction made by Kolbe and co-workers that a hexapeptide with hydrophobic residues at three positions is a conserved chaperone binding motif. Because the hydrophobic groove on the concave side of translocator chaperones is involved in binding of the major and the minor translocator, simultaneous binding of both translocators to a single type III secretion class II chaperone appears unlikely.
\end{abstract}

Keywords: Bacterial virulence factor, Chaperone, Complex, Crystal structure, Dimer, Peptide binding, Protein-protein interaction, Tetratricopeptide repeat, Translocator, Type III secretion

\footnotetext{
* Correspondence: Hartmut.Niemann@uni-bielefeld.de

Department of Chemistry, Bielefeld University, PO Box 100131

33501, Bielefeld, Germany
} 


\section{Background}

A wide range of pathogenic Gram-negative bacteria use a type III secretion system (T3SS) to facilitate the transport of cytotoxins, so called effector proteins, into the host cell. These effectors influence and manipulate diverse cellular pathways for the pathogens' benefit resulting e.g. in a repression of the inflammatory response or altered phagocytosis [1,2]. This allows the bacteria to thrive undetected by the host's immune system.

Effector translocation occurs via the injectisome, a needlelike multi-protein complex evolutionarily related to the bacterial flagellum. The injectisome's basal body spans the whole bacterial envelope eventually narrowing into a hollow needle protruding from the bacterial surface. The effectors pass the host cell membrane through pores formed by translocator proteins arranging in a ring like structure (for detailed reviews see [3-6]). The ring forming translocator proteins are sub-divided in the major and the minor translocator. Though both proteins exhibit a hydrophobic nature and exist in oligomeric states, they share almost no sequence homology. The major translocator holds an N-terminal coiled-coil domain, the crystal structure of which was recently reported [7], and two predicted transmembrane helices as common and conserved features between species. Major translocators have been shown to insert into membranes even in absence of the hydrophobic binding partner [8-10]. Nevertheless the minor translocator is essential for the formation of a functional pore $[10,11]$. The minor translocator only features one predicted transmembrane region, a coiled-coil domain and a Cterminal amphipathic region, which is important for the binding to the hydrophilic translocator (LcrV in Yersinia spp.). The proteins are well conserved between species and have been shown to exist in a partly unfolded and disordered state that seems to be necessary for translocation and pore formation (for detailed review see [12]). In some cases the minor translocator is additionally involved in regulatory processes [13].

For efficient export both hydrophobic translocators and several effectors need specific chaperones that stabilize them in the bacterial cytosol prior to export. In contrast to classic chaperones like DnaK or GroEL these proteins lack the ability to bind and hydrolyze ATP. T3S chaperones have been divided into three subgroups: Class I chaperones interacting with effector proteins, class II chaperones interacting with the translocators and class III chaperones interacting with T3SS needle components (for detailed reviews see [1416]). T3S chaperones prevent premature aggregation and keep their substrates in a partially unfolded state so that they are able to pass the narrow channel of the secretion needle. A hexameric ATPase associated to the cytoplasmic side of the T3S export apparatus powers chaperone release and further unfolding of effectors $[17,18]$. Deletion of the hexameric ATPase was also shown to impair secretion of a translocon protein [19].
SycD (specific Yop chaperone D) from the enteropathogen Yersinia enterocolitica is the class II chaperone of the translocator proteins YopD (Yersinia outer protein D) and YopB (Yersinia outer protein B) [20]. Like all known class II chaperones SycD exhibits an all $\alpha$-helical structure [21]. Six helices (H1A, H1B, H2A, H2B, H3A, H3B) fold into three tetratricopeptide repeats (TPRs), tandemly arranged motifs of some 34 amino acids length [22]. An extra Cterminal helix (H8) probably exerts a stabilizing function. TPRs generally provide platforms for protein-protein interactions. They are e.g. found in one protein of the heterodimeric chaperones for the T3SS needle proteins [23-25]. The superhelical arrangement of tandem TPRs results in a curved structure with a convex outer surface and a concave inner side, which forms a mostly hydrophobic groove in T3S class II chaperones. Crystal structures of SycD homologs in complex with peptides from their cognate translocator proteins have shown that the concave surface provides a binding site for the translocator proteins. Recently, Lunelli et al. identified a short binding motif $\left({ }^{65} \mathrm{PELKAP}^{70}\right)$ within the Shigella major translocator IpaB that binds into the concave groove of its chaperone IpgC [26]. Based on these results they further suggested that similar motifs in other translocators including the Yersinia proteins YopD and YopB are also involved in chaperone binding. Subsequently Dessen and co-workers revealed that the concave groove of the Pseudomonas chaperone $\mathrm{PcrH}$ constitutes the binding platform for the minor translocator PopD sequence ${ }^{49}$ VELNAP ${ }^{54}$ showing high similarity to the IpgC:IpaB binding motif [27].

Here we present the structure of the class II chaperone $\mathrm{SycD}$ in complex with a peptide of the $\mathrm{N}$-terminal region of the minor translocator YopD comprising the recently proposed sequence motif PELIKP. The peptide binds in an elongated form into the chaperone's concave groove where three highly conserved hydrophobic residues point into three conserved hydrophobic pockets formed by the chaperone. These results underline that class II T3S chaperones recognize the major and the minor translocator via a common sequence motif that is present in a wide range of T3S translocator proteins.

\section{Results}

Peptide-bound SycD crystallized as a kinked head-to-head dimer

In order to verify that YopD binds to SycD via the proposed sequence motif ${ }^{58}$ PELIKP ${ }^{63}$ [26] we co-crystallized N- and C-terminally truncated $\mathrm{SycD}_{21-163}$ with a synthetic peptide corresponding to $\mathrm{YopD}_{56-65}\left({ }^{56} \mathrm{QVPELIKPSQ}^{65}\right)$. The chaperone peptide complex crystallized in the trigonal space group $\mathrm{P} 3_{1} 21$ with one monomer per asymmetric unit. The structure was solved to a resolution of $2.5 \AA$ by molecular replacement using $\mathrm{SycD}_{21-163}$ (PDB-ID: 2VGY) as search model. Clearly visible Fo-Fc difference electron density 
within the concave groove revealed that the peptide had been successfully co-crystallized with $\mathrm{SycD}_{21-163}$. Data collection and refinement statistics are listed in Table 1.

The crystal packing of the peptide-bound variant of SycD reveals a 2-fold symmetric dimer (Figure 1A) that is very similar to the alternative kinked dimer of apo $\mathrm{SycD}_{21}$ 163 (PDB-ID: 2VGY) (Figure 1C, D), one of two possible elongated dimers previously described by Büttner et al. [21]. The dimerization site consists of both helices of the

Table $1 \mathrm{X}$-ray data-collection and refinement statistics

\begin{tabular}{|c|c|}
\hline & $\mathrm{SycD}_{21-163} / \mathrm{YopD}$ \\
\hline \multicolumn{2}{|l|}{ Data collection } \\
\hline Wavelength ( $(\AA)$ & 0.918 \\
\hline Space group & $P 3,21$ \\
\hline \multicolumn{2}{|l|}{ Unit cell parameters } \\
\hline$a, b, c(\AA)$ & $106.4,106.4,52.0$ \\
\hline$a, \beta, \gamma\left(^{\circ}\right)$ & $90,90,120$ \\
\hline Resolution range $(\AA)$ & $25-2.5(2.64-2.5)$ \\
\hline No. observed/unique reflections & $166476 / 11931$ \\
\hline Completeness & $99.4(97.0)$ \\
\hline Multiplicity & $14.0(10.0)$ \\
\hline $\mathrm{R}_{\text {merge }}(\%)^{*}$ & $10.6(57.1)$ \\
\hline Mean $I / \sigma(I)$ & $18.5(3.1)$ \\
\hline Wilson B factor $\left(\AA^{2}\right)$ & 79.6 \\
\hline \multicolumn{2}{|l|}{ Refinement } \\
\hline $\mathrm{R}_{\text {work }} / \mathrm{R}_{\text {free }}(\%)^{\S}$ & 19.0/23.8 (31.3/34.8) \\
\hline \multicolumn{2}{|l|}{ Mean B factor $\left(\AA^{2}\right)$} \\
\hline Overall & 79.2 \\
\hline Protein & 78.1 \\
\hline Peptide & 84.0 \\
\hline Ligand/ion & 105.3 \\
\hline Water & 75.3 \\
\hline \multicolumn{2}{|l|}{ No. of atoms } \\
\hline Protein/peptide & 1127 \\
\hline Ligand/ion & 35 \\
\hline Water & 17 \\
\hline \multicolumn{2}{|l|}{ R.m.s.d. } \\
\hline bond $(\AA)$ & 0.007 \\
\hline angle $\left(^{\circ}\right)$ & 1.061 \\
\hline \multicolumn{2}{|l|}{ Ramachandran } \\
\hline favored (\%) & 95.6 \\
\hline allowed (\%) & 4.4 \\
\hline
\end{tabular}

$* \mathrm{R}_{\text {merge }}=\Sigma_{\text {hkl }} \Sigma_{i}\left|\mathrm{l}_{\mathrm{i}}(\mathrm{hkl})-\mathrm{I}\langle(\mathrm{hkl})\rangle\right| / \Sigma_{h k l} \Sigma_{i} \mathrm{l}_{\mathrm{i}}(h k l)$ where $\mathrm{l}_{i}(\mathrm{hkl})$ is the $i$ th measurement of the reflection (hkl).

${ }^{\S} \mathrm{R}_{\text {work }} / \mathrm{R}_{\text {free }}=\Sigma_{\text {hkl }}|| \mathrm{F}_{\text {obs }}|-| \mathrm{F}_{\text {calc }}|| / \Sigma_{h k l}|| \mathrm{F}_{\text {obs }}|| \mathrm{R}_{\text {work }}$ was calculated from the work set. $\mathrm{R}_{\text {free }}$ was calculated from the test set encompassing $4.9 \%$ of the total reflections. The test set was not used in refinement. Values in parentheses belong to the highest resolution shell. first tetratricopeptide repeat (TPR1) (Figure 1B) with a buried surface area of $710 \AA^{2}$ per monomer as defined by the PISA server [28] and mainly involves the hydrophobic residues Leu42, Val58, Ala61 and Leu65. The residues Leu65 and Ala61 have previously been shown to be essential for SycD dimer formation [21].

A pairwise comparison done by the DALI Lite server [29] showed that the SycD protomer in the crystal structure of the $\mathrm{SycD}_{21-163}: \mathrm{YopD}$ complex is structurally very similar to the $\mathrm{SycD}_{21-163}$ protomer from crystal form 2 (kinked dimer, PDB-ID: 2VGY) with a root mean square deviation (r.m.s.d.) of $0.8 \AA$ and to both chains of $\mathrm{SycD}_{21}$ 163 crystal form 1 (elongated dimer, PDB-ID: 2VGX) with an r.m.s.d. of $0.9 \AA$ for monomer $\mathrm{A}$ and an r.m.s.d. of $1.2 \AA$ for monomer $\mathrm{B}$ for $\mathrm{C} \alpha$-atoms. The residues lining the concave groove do not show significant conformational changes between the apo and the peptide-bound form, suggesting a preformed and largely rigid binding site. Yet small differences exist with regard to the position and angle of the stabilizing helix $\mathrm{H} 8$ suggesting that it is somewhat flexible. However, except for residue Arg146 helix H8 does not contribute to peptide binding. Arg146 seems to be relatively flexible in the SycD apo forms but is fixed in the complex structure via hydrogen bonds to Glu142 and the peptide residue Gln56' (apostrophe further denotes YopD peptide residues). The ordering of Arg146 in the complex is partly also brought about by contacts to Gln131 and Phe128 of a neighboring monomer, and may thus be due to crystal packing rather than peptide binding.

\section{The YopD sequence motif is recognized by the concave groove of SycD}

The Fo-Fc difference map clearly revealed positive electron density within the concave groove of $\mathrm{SycD}_{21-163}$ (Figure 2A), which allowed the easy positioning of the peptide residues 56'-64' whereas Gln65' could not be placed due to missing electron density. The peptide binds in an extended form into the chaperone's hydrophobic cleft that is lined by aromatic and aliphatic residues from helix H1A and $\mathrm{H} 2 \mathrm{~A}$ (Figure $2 \mathrm{~B}$ ). The antiparallel orientation relative to helix H1A allows the peptide's hydrophobic residues Pro58', Leu60' and Pro63' to perfectly fit into three distinct hydrophobic pockets (Figure $2 \mathrm{C}$ ) within the concave groove whereas the charged residues Glu59' and Lys62' point outwards without contacting the chaperone. The pocket for Leu60' of the peptide is exclusively hydrophobic and is mainly built by the SycD residues Phe44, Tyr47 (H1A), Phe59 (H1B), Leu74, Gly75 and Ala78 (H2A) (Figure 2B). Pro63' resides on a smaller hydrophobic patch consisting of Tyr40 and Phe44 (H1A). The region of the concave groove that binds Pro58' has a mixed hydrophobic and polar character and is formed by Tyr47 (H1A), Ala78 (H2A), Gln81 (H2A), Tyr93 (H2B) and His109 (H3A). Van der Waals contacts between Tyr52 and Ala82 from SycD 


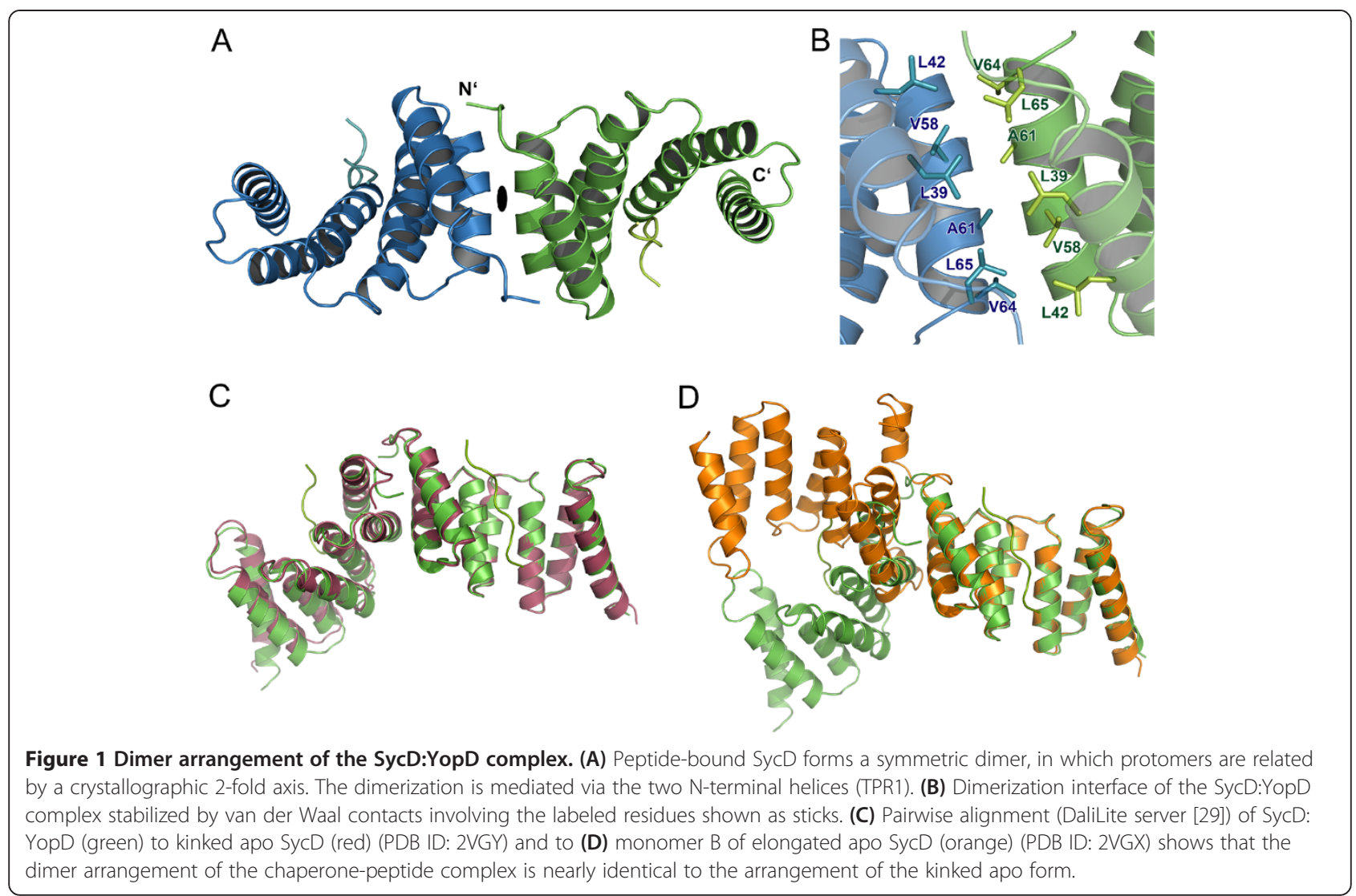

and Val57' of the peptide and between Leu74 of SycD and Ile61' of the peptide further support the complex. Direct hydrogen bonds are formed between the hydroxyls of SycD Tyr40 and Tyr47 and the carbonyl oxygen of the peptide residues Ile61' and Pro58, respectively, and between the guanidino group of Arg146 (H8) and the side chain of Gln56'. In addition, there are several water mediated interactions between $\mathrm{SycD}$ and the YopD peptide.

Structure based sequence alignments (see [27]) revealed that the chaperone binding domain (CBD) harbors three evolutionary highly conserved residues, which have been identified to be essential for the PcrH:PopD and IpgC:IpaB complex formation $[26,27]$. These are interspaced by unspecific, mostly hydrophilic residues that may merely function as spacers leading to the common motif $\mathrm{P} / \mathrm{VxLxxP}$, where $\mathrm{x}$ is either hydrophilic or hydrophobic. Based on these results it is evident that YopD residues Pro58, Leu60' and Pro63' correspond to IpaB Pro65, Leu67 and Pro70 and to PopD Val49, Leu51 and Pro54. Furthermore a superposition of the chaperone $C \alpha$-atoms of SycD:YopD with PcrH:PopD (PDB-ID: 2XCB, chain A) and IpgC:IpaB (PDB-ID: 3GZ1, chain B) with an r.m.s.d. of $1.0 \AA$ and $1.2 \AA$, respectively, showed that the minor translocator YopD binds $\mathrm{SycD}$ in a similar fashion (Figure 3). In all three chaperones the bound peptide fragments adopt a nearly identical conformation within the main sequence motif leading to a very good overlap of the three hydrophobic key residues that occupy the same hydrophobic patches.

\section{Discussion}

One unexpected finding of this work is the SycD quaternary structure. We had previously shown that mutations in helix $\mathrm{H} 1 \mathrm{~B}$ result in monomeric SycD, thereby mapping the homodimerization interface to TPR1 [21]. However, the precise quaternary structure remained ambiguous, because two different crystal forms revealed different arrangements of the protomers in the SycD dimer, an extended and a kinked one [21]. The elongated dimer (PDB ID: 2VGX) had a larger buried surface area, a better shape correlation and a smaller gap volume index, suggesting that it is more likely to represent the solution dimer. Surprisingly, the structure reported here contains a SycD homodimer that is virtually identical to the kinked $\mathrm{SycD}$ dimer reported previously (PDB ID: 2VGY). Crystals of the SycD:YopD complex and the kinked apo form of SycD are not isomorphous and in different space groups. This suggests that the kinked dimer may be more favorable than initially thought [31].

Ambiguity and variability of their quaternary structures appears to be a recurring theme among T3S translocator chaperones. Formation of higher oligomers has been 


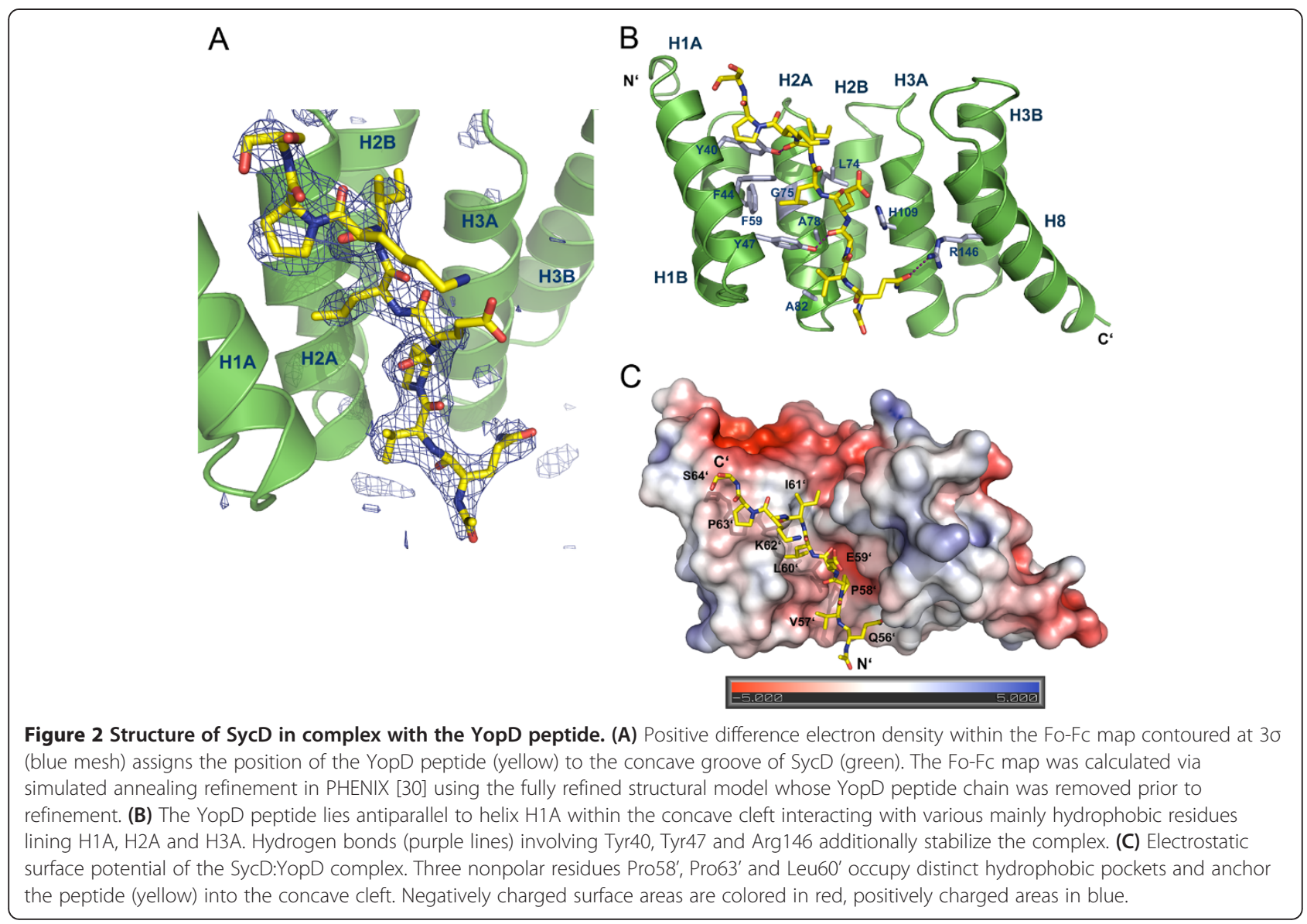

reported for full-length SycD [32] or Salmonella enterica SicA [33]. It is of note that homodimers of T3S class II chaperones are not constitutive. PcrH shows monomer-dimer equilibrium [27]. Moreover, binding of translocators often disrupts the dimer interaction, resulting in 1:1 complexes $[27,34,35]$, although binding of a single translocator to a dimeric chaperone has also been reported [36]. The arrangement of protomers in the chaperone dimers is under debate in several cases as well. For IpgC two different asymmetric dimers [26] and another 2-fold symmetric dimer involving TPR1 [37] were reported. The crystal structure of PcrH shows two quaternary structures that might be stable in solution, an asymmetric dimer mediated by contacts of the convex side (back-to-back dimer) and a 2-fold symmetric dimer mediated by TPR1 (head-to-head) [27]. For PcrH, no functional data is available to decide which of these dimers is present in solution.

Previous studies had led to the identification of two regions within YopD that are essential for SycD binding [38], one involving the C-terminal amphipathic domain (aa 278-292) and another one located $\mathrm{N}$-terminally encompassing the residues 53-149, which also contains the six amino acid consensus sequence for binding to class II chaperones identified by Kolbe and co-workers [26]. The concave groove of TPR proteins can accommodate interaction partners in helical $[24,25,39,40]$ or extended conformation [41-43]. Accordingly the SycD concave groove was proposed to bind the amphipathic YopD Cterminus in helical conformation [44] or a short conserved peptide from the $\mathrm{N}$-terminal region in extended conformation [26]. Our structure verifies that the YopD consensus peptide binds to SycD in the manner predicted by Kolbe and coworkers based on their IpgC:IpaB complex structure [26]. The peptide's three conserved anchor residues bind into distinct binding pockets within the concave region leading to a peptide conformation that is nearly identical to that of the CBDs of PopD and IpaB in complex with their respective chaperones $[26,27]$. This allows understanding how TPR-like chaperones that are well conserved between species (sequence identity SycD/PcrH: $59 \%$, SycD/IpgC: $28 \%$, (see also [21,26])) bind to their respective cargo that exhibits a lower degree of sequence conservation (sequence identity (1) minor translocator: YopD/ PopD:41\%, YopD/IpaC: 20\%; (2) major translocator YopB/ PopB: $43 \%$, YopB/IpaB: 17\% (see also [12,27])) and how they recognize with high specificity two different substrates that share nearly no common sequence features. The presence of the consensus motif for binding of the chaperone's hydrophobic groove in both the major and the minor translocator from the same species suggests that binding of translocators to the 


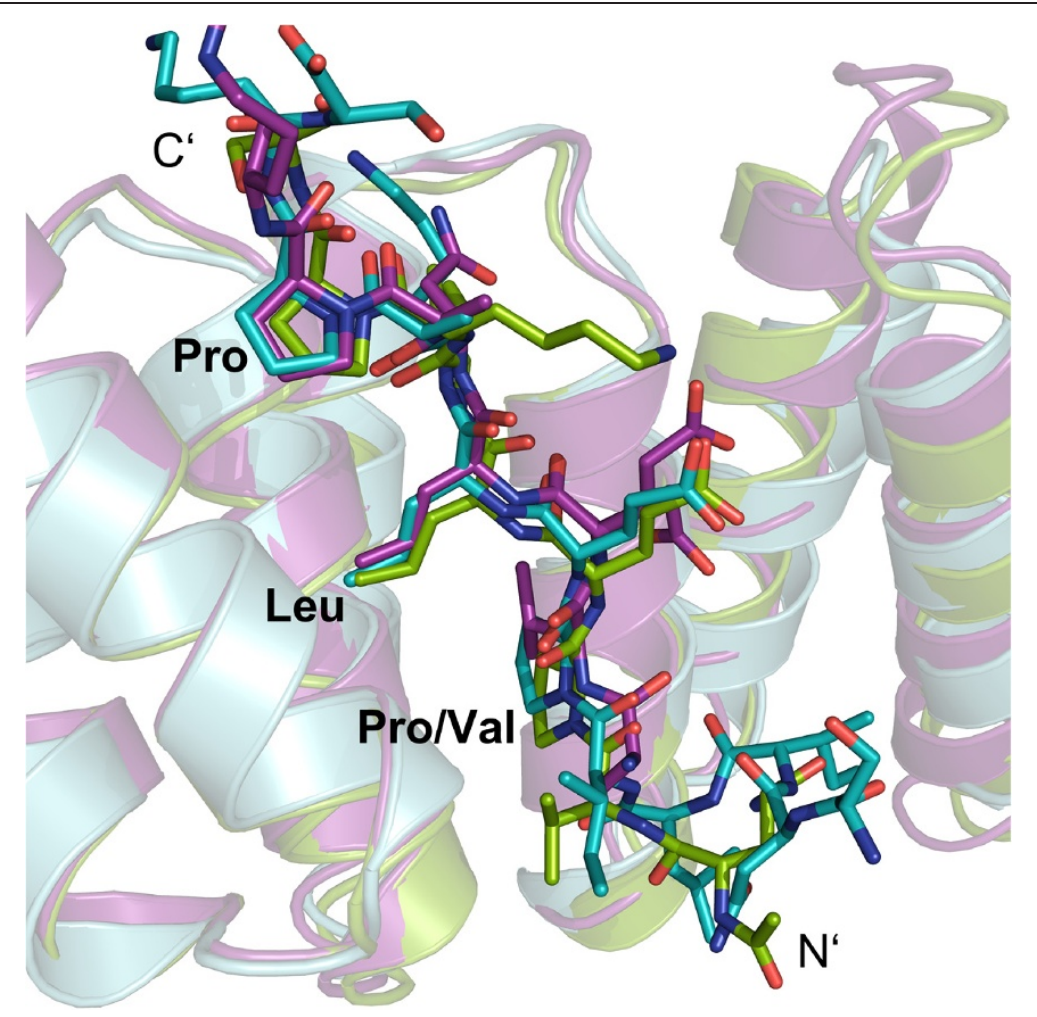

Figure 3 Superposition of the chaperone binding domains of T3S translocators. The superposition (DaliLite server [29]) of the chaperonepeptide complexes SycD:YopD (green), PcrH:PopD (purple) (PDB ID: 2XCB, chain A) and IpgC:IpaB (cyan) (PDB ID: 3GZ1, chain B) reveals a good spatial agreement within the key anchor residues of the YopD, PopD and IpaB sequence motifs.

chaperone is mutually exclusive and formation of a ternary complex should not be possible. The data in the literature with regard to this issue is not univocal and the situation may well differ between species $[27,35,36,45,46]$. In some cases, e.g. in Edwardsiella tarda, each hydrophobic translocator even requires its own chaperone $[47,48]$.

The hydrophobic cleft of SycD is lined by aromatic residues, mainly tyrosines, which have been shown to appear with high prevalence in a wide range of protein interaction surfaces [49]. These residues are highly conserved within T3S class II chaperones although they are located at noncanonical positions $[21,34,44]$. Tyr40 and Tyr47 are not only involved in the formation of hydrophobic patches but also keep the peptide in the correct conformation by providing a functional group for hydrogen bond formation with the peptide backbone. The existence of very similar interactions in the chaperone-peptide complexes of IpgC from Shigella [26] and PcrH from Pseudomonas [27] underlines the importance hereof. Thus it is not surprising, that mutations within the conserved aromatic ladder of helix H1A (Tyr40, Phe44, Tyr47 in SycD) have severe effects on the recognition and binding of YopD and YopB [50]. Based on the present structure it is not possible to rationalize why several mutations that map to canonical TPR positions or the binding groove should affect binding and/or secretion only of YopB but not of YopD [50]. Mutations affecting secretion only of YopD but not YopB were mapped to the convex side (L42A, H67A and L76A), which thus was considered to be SycD's main binding region for YopD, with additional contributions from the loop connecting $\mathrm{H} 2 \mathrm{~B}$ and $\mathrm{H} 3 \mathrm{~A}$ $[38,50,51]$. These observations may be explained by the fact that the CBD represents only a small part of a longer $\mathrm{N}$ terminal binding region that together with the C-terminal amphipathic domain is involved in SycD binding. Furthermore, the residual part (aa 150-287) of the minor translocator has been shown to exist in a partially unfolded molten globule state [52]. Thus one might assume that YopD and most likely YopB are recognized by the chaperone's concave cleft through the conserved binding motif. The partly unfolded region of the protein could wrap around SycD so that YopD might contact the convex side with the remaining binding regions.

\section{Conclusions}

Compared to the effector binding chaperones of T3SSs still only little is now about the TPR-like class II chaperones especially concerning the chaperone translocator interaction. This is mainly due to the hydrophobic nature 
and thus delicate handling of the translocator proteins. By co-crystallizing SycD with a synthetic peptide, we were able to show that the concave side of SycD interacts with a conserved chaperone binding hexapeptide of the minor translocator YopD. These results underline the fact that T3S TPR-like chaperones bind their substrates via a common mechanism that is highly conserved between different species. However, several questions remain. The exact quaternary structure in solution is currently not established for any of the T3S translocator chaperones for which crystal structures are available. Complementary techniques like solution small angle scattering may help to resolve this issue. Moreover, the current structures of chaperones bound to short translocator peptides do not explain why binding of substrates causes dissociation of the chaperone homodimers and results in heterodimeric 1:1 complexes in many cases. Thus, T3S translocators, their chaperones and the complexes formed between them remain an exciting topic for structural studies.

\section{Methods}

\section{Protein expression and purification}

Expression of glutathione-S-transferase (GST)-tagged Syc $\mathrm{D}_{21-163}$ was performed as described [21] in E. coli BL21 (DE3) RIL transformed with the expression vector pGEX-6P-1_sycD21-163. Bacteria were grown in LB medium at $37^{\circ} \mathrm{C}$ to $\mathrm{OD}_{600} \sim 0.4-0.5$. The temperature was reduced to $20^{\circ} \mathrm{C}$ and incubation was continued to $\mathrm{OD}_{600} \sim$ 0.8 . Protein expression was induced by adding $0.25 \mathrm{mM}$ isopropyl- $\beta$-D-thio-galactopyranoside (IPTG) and was carried out for $16-18 \mathrm{~h}$ at $20^{\circ} \mathrm{C}$. Pelleted cells were resuspended in phosphate buffered saline (PBS) containing $10 \mathrm{mM}$ ß-mercaptoethanol, 1 tablet Complete protease inhibitor cocktail (Roche) and DNase and lysed using a French pressure cell press. The lysate was centrifuged at $16 ' 000 \mathrm{xg}$. The supernatant was added to a glutathione sepharose matrix equilibrated with $\mathrm{PBS} \mathrm{pH}$ 7.4, $10 \mathrm{mM} \beta$ mercaptoethanol and incubated for $1 \mathrm{~h}$ at $4^{\circ} \mathrm{C}$. The column was washed extensively with PBS and with 2-3 column volumes $50 \mathrm{mM}$ Tris $\mathrm{pH} 7.4,200 \mathrm{mM} \mathrm{NaCl}$, $0.5 \mathrm{mM}$ EDTA, $10 \mathrm{mM} \beta$-mercaptoethanol. The GST-tag was cleaved off with PreScission Protease in 2-3 column volumes of the same buffer containing $40 \mu \mathrm{M}$ Pefabloc and $0.3 \mu \mathrm{M}$ aprotinin for $\sim 48-66 \mathrm{~h}$ at $4^{\circ} \mathrm{C}$. The cleaved protein was eluted and dialysed against $50 \mathrm{mM}$ Tris $\mathrm{pH} 8$, $4 \mathrm{mM}$ dithiothreitol (DTT). $\mathrm{SycD}_{21-163}$ was further purified via anion exchange chromatography (Source 15Q, GE Healthcare) using a linear $\mathrm{NaCl}$ gradient with $50 \mathrm{mM}$ Tris $\mathrm{pH}$ 8, $4 \mathrm{mM}$ DTT, $1 \mathrm{M} \mathrm{NaCl}$ as high salt buffer followed by size exclusion chromatography (Superdex 75 16/60, GE Healthcare) equilibrated with $20 \mathrm{mM}$ Tris $\mathrm{pH} 8,50 \mathrm{mM}$ $\mathrm{NaCl}, 1 \mathrm{mM}$ DTT. The protein was concentrated to $\sim 15 \mathrm{mg} / \mathrm{ml}$ and stored at $-80^{\circ} \mathrm{C}$ until further use.

\section{Crystallization}

A synthetic peptide corresponding to $\mathrm{YopD}_{56-65}$ (Ac-QVPELIKPSQ- $\mathrm{NH}_{2}$ ) was purchased from EMC microcollections (Tübingen). For co-crystallization experiments the YopD peptide was dissolved in $20 \mathrm{mM}$ Tris $\mathrm{pH} 8,50 \mathrm{mM} \mathrm{NaCl}$, $1 \mathrm{mM}$ DTT with a concentration of $6 \mathrm{mM}$ and mixed with $\mathrm{SycD}_{21-163}$ in the same buffer in a molar ratio of 1:1.3 (SycD:Peptide). Initial crystallization conditions were found using commercially available screens (Qiagen). Final crystals were grown at $20^{\circ} \mathrm{C}$ using the vapor diffusion method in optimized conditions containing $50 \mathrm{mM}$ MES $\mathrm{pH}$ 6, $50 \mathrm{mM}$ citrate $\mathrm{pH} 5,1.1-1.4 \mathrm{M}\left(\mathrm{NH}_{4}\right)_{2} \mathrm{SO}_{4}$, a drop ratio of 1:0.5 protein:reservoir and a protein concentration of $8 \mathrm{mg} /$ $\mathrm{mL}$. Single crystals were harvested, cryoprotected with $15 \%$ 2,3-butanediol in mother liquor and flash frozen in liquid nitrogen.

\section{Data collection, structure determination and refinement}

Diffraction data were collected at $100 \mathrm{~K}$ and a wavelength of $0.918 \AA$ at Beamline 14.2 at BESSY II (Berlin) on a Rayonics MX-225 CCD detector with an oscillation range of $0.3^{\circ}$ or $0.5^{\circ}$. Data were indexed and integrated with XDS [53], merged in POINTLESS and scaled with SCALA [54] from the CCP4 suite [55]. Phases were obtained via molecular replacement in PHASER [56] using $\mathrm{SycD}_{21-163}$ (PDB-ID: 2VGY) as search model. Model building was carried out in COOT 0.6.2 [57] and the structure was refined with PHENIX.REFINE 1.7.2 [30]. The structure was validated using the MolProbity server [58] and the validation tools implemented in COOT. The YopD peptide was built and refined with an occupancy of 1.0. This approach was validated by a final refinement, in which the starting occupancy of the YopD peptide was set to 0.5 and a single group occupancy was refined for the whole peptide, resulting in a refined occupancy of 0.97. Using the output model as input for a second round of refinement led to an occupancy of 1.0 for the YopD peptide. For the calculation of a weighted 2Fo-Fc and Fo-Fc map showing the position of the peptide ligand, the YopD peptide chain was removed from the fully refined model prior to ten macrocycles of simulated annealing refinement in PHENIX. Figures were created with PyMOL [59]. The electrostatic surface potential of the $\mathrm{SycD}_{21-163}$ : YopD $_{56-65}$ complex was calculated with the APBS [60] plugin of PyMOL using default settings.

\section{Abbreviations}

CBD: Chaperone binding domain; DTT: Dithiothreitol; GST: Glutathione-Stransferase; Syc: Specific yop chaperone; T3SS: Type III secretion system; TPR: Tetratricopeptide repeat; Yop: Yersinia outer protein.

\section{Competing interests}

The authors declare that they have no competing interests.

\section{Authors' contributions}

HHN conceived the study. MS purified protein, processed data, and solved and refined the structure. MS and HHN designed experiments, collected 
diffraction data, evaluated results and wrote the manuscript. All authors read and approved the final manuscript.

\section{Acknowledgements}

We thank Christina Geerds for expert technical assistance in protein purification and crystallization. We gratefully acknowledge access to beamline BL14.2 of the BESSY II storage ring (Berlin, Germany), where diffraction data were collected. We gratefully acknowledge coverage of travel expenses for data collection by the Helmholtz Zentrum Berlin (HZB). We acknowledge support of the publication fee by Deutsche Forschungsgemeinschaft (DFG) and the Open Access Publication Funds of Bielefeld University. This work was supported by young scientists' grant no. 2218-1970.13/2008 of the German Israeli Foundation (GIF) to H.H.N. Work in the Niemann lab was also supported by the DFG collaborative research center SFB 613. Funding bodies had no role in design, in the collection, analysis, and interpretation of data; in the writing of the manuscript; and in the decision to submit the manuscript for publication.

Received: 8 March 2012 Accepted: 18 June 2012

Published: 18 June 2012

\section{References}

1. Dean P: Functional domains and motifs of bacterial type III effector proteins and their roles in infection. FEMS Microbiol Rev 2011, 35:1100-1125.

2. Trosky JE, Liverman ADB, Orth K: Yersinia outer proteins: Yops. Cell Microbiol 2008, 10:557-565

3. Cornelis GR: The type III secretion injectisome. Nat Rev Micro 2006, 4:811-825.

4. Izoré T, Job V, Dessen A: Biogenesis, Regulation, and Targeting of the Type III Secretion System. Structure 2011, 19:603-612.

5. Troisfontaines P, Cornelis GR: Type III Secretion: More Systems Than You Think. Physiology 2005, 20:326-339.

6. Wang Y, Zhang L, Picking WL, Picking WD, de Guzman RN: Structural dissection of the extracellular moieties of the type III secretion apparatus. Mol Biosyst 2008, 4:1176

7. Barta ML, Dickenson NE, Patil M, Keightley A, Wyckoff GJ, Picking WD, Picking WL, Geisbrecht BV: The Structures of Coiled-Coil Domains from Type III Secretion System Translocators Reveal Homology to PoreForming Toxins. J Mol Biol 2012, 417:395-405.

8. Shaw RK, Daniell S, Ebel F, Frankel G, Knutton S: EspA filament-mediated protein translocation into red blood cells. Cell Microbiol 2001, 3:213-222.

9. Hume PJ, McGhie EJ, Hayward RD, Koronakis V: The purified Shigella IpaB and Salmonella SipB translocators share biochemical properties and membrane topology. Mol Microbiol 2003, 49:425-439.

10. Goure J, Pastor A, Faudry E, Chabert J, Dessen A, Attree I: The V antigen of Pseudomonas aeruginosa is required for assembly of the functional PopB/PopD translocation pore in host cell membranes. Infect Immun 2004, 72:4741-4750.

11. Blocker A, Gounon P, Larquet E, Niebuhr K, Cabiaux V, Parsot C, Sansonetti P: The tripartite type III secreton of Shigella flexneri inserts IpaB and IpaC into host membranes. J Cell Biol 1999, 147:683-693.

12. Matteï $P$, Faudry E, Job V, Izoré T, Attree I, Dessen A: Membrane targeting and pore formation by the type III secretion system translocon. FEBS $J$ 2011, 278:414-426.

13. Chen $Y$, Anderson DM: Expression hierarchy in the Yersinia type III secretion system established through YopD recognition of RNA. MOl Microbiol 2011, 80:966-980.

14. Feldman MF, Cornelis GR: The multitalented type III chaperones: all you can do with 15 kDa. FEMS Microbiol Lett 2003, 219:151-158.

15. Parsot C: The various and varying roles of specific chaperones in type III secretion systems. Curr Opin Microbiol 2003, 6:7-14.

16. Wilharm G, Dittmann S, Schmid A, Heesemann J: On the role of specific chaperones, the specific ATPase, and the proton motive force in type III secretion. Int J Med Microbiol 2007, 297:27-36.

17. Akeda Y, Galán JE: Chaperone release and unfolding of substrates in type III secretion. Nature 2005, 437:911-915.

18. Galán JE: Energizing type III secretion machines: what is the fuel? Nat Struct Mol Biol 2008, 15:127-128.

19. Lorenz C, Buttner D: Functional Characterization of the Type III Secretion ATPase HrcN from the Plant Pathogen Xanthomonas campestris pv. vesicatoria. J Bacterio/ 2009, 191:1414-1428.
20. Neyt C, Cornelis GR: Role of SycD, the chaperone of the Yersinia Yop translocators YopB and YopD. Mol Microbiol 1999, 31:143-156.

21. Büttner CR, Sorg I, Cornelis GR, Heinz DW, Niemann HH: Structure of the Yersinia enterocolitica Type III Secretion Translocator Chaperone SycD. $J$ Mol Biol 2008, 375:997-1012.

22. Blatch $G L$, Lässle $M$ : The tetratricopeptide repeat: a structural motif mediating protein-protein interactions. Bioessays 1999, 21:932-939.

23. Chatterjee C, Kumar S, Chakraborty S, Tan YW, Leung KY, Sivaraman J, Mok Y, Cobine P: Crystal Structure of the Heteromolecular Chaperone, AscEAscG, from the Type III Secretion System in Aeromonas hydrophila. PLoS One 2011, 6:e19208.

24. Quinaud M, Ple S, Job V, Contreras-Martel C, Simorre J, Attree I, Dessen A: Structure of the heterotrimeric complex that regulates type III secretion needle formation. Proc Natl Acad Sci 2007, 104:7803-7808.

25. Sun P, Tropea JE, Austin BP, Cherry S, Waugh DS: Structural Characterization of the Yersinia pestis Type III Secretion System Needle Protein YscF in Complex with Its Heterodimeric Chaperone YscE/YscG. Mol Biol 2008, 377:819-830

26. Lunelli M, Lokareddy RK, Zychlinsky A, Kolbe M: IpaB-IpgC interaction defines binding motif for type III secretion translocator. Proc Natl Acad Sci 2009, 106:9661-9666.

27. Job V, Mattei P, Lemaire D, Attree I, Dessen A: Structural Basis of Chaperone Recognition of Type III Secretion System Minor Translocator Proteins. J Biol Chem 2010, 285:23224-23232.

28. Krissinel $E_{1}$ Henrick K: Inference of macromolecular assemblies from crystalline state. J Mol Biol 2007, 372:774-797.

29. Holm L, Park J: DaliLite workbench for protein structure comparison. Bioinformatics 2000, 16:566-567.

30. Adams PD, Afonine PV, Bunkóczi G, Chen VB, Davis IW, Echols N, Headd JJ, Hung L, Kapral GJ, Grosse-Kunstleve RW, McCoy AJ, Moriarty NW, Oeffner R, Read RJ, Richardson DC, Richardson JS, Terwilliger TC, Zwart PH: PHENIX. Acta Crystallogr D: Biol Crystallogr 2010, 66:213-221.

31. Xu Q, Canutescu AA, Wang G, Shapovalov M, Obradovic Z, Dunbrack RL: Statistical analysis of interface similarity in crystals of homologous proteins. J Mol Biol 2008, 381:487-507.

32. Schmid A, Dittmann S, Grimminger V, Walter S, Heesemann J, Wilharm G: Yersinia enterocolitica type III secretion chaperone SycD: Recombinant expression, purification and characterization of a homodimer. Protein Expr Purif 2006, 49:176-182.

33. Priyadarshi A, Tang L: Crystallization and preliminary crystallographic analysis of the type III secretion translocator chaperone SicA from Salmonella enterica. Acta Crystallogr F: Struct Biol Cryst Commun 2010, 66:1533-1535.

34. Basu A, Chatterjee R, Datta S: Expression, Purification, Structural and Functional Analysis of SycB: A Type Three Secretion Chaperone From Yersinia enterocolitica. Protein J 2012, 31:93-107.

35. Tan YW, Yu HB, Sivaraman J, Leung KY, Mok Y: Mapping of the chaperone $\mathrm{Acr} H$ binding regions of translocators $\mathrm{AopB}$ and $\mathrm{AopD}$ and characterization of oligomeric and metastable AcrH-AopB-AopD complexes in the type III secretion system of Aeromonas hydrophila. Protein Sci 2009, 18:1724-1734.

36. Lokareddy RK, Lunelli M, Eilers B, Wolter V, Kolbe M: Combination of two separate binding domains defines stoichiometry between type III secretion system chaperone IpgC and translocator protein IpaB. J Biol Chem 2010, 285:39965-39975.

37. Barta ML, Zhang L, Picking WL, Geisbrecht BV: Evidence for alternative quaternary structure in a bacterial Type III secretion system chaperone. BMC Struct Biol 2010, 10:21

38. Francis MS, Aili M, Wiklund M, Wolf-Watz H: A study of the YopD-LcrH interaction from Yersinia pseudotuberculosis reveals a role for hydrophobic residues within the amphipathic domain of YopD. Mol Microbiol 2000, 38:85-102.

39. Abe Y, Shodai T, Muto T, Mihara K, Torii H, Nishikawa S, Endo T, Kohda D: Structural basis of presequence recognition by the mitochondrial protein import receptor Tom20. Cell 2000, 100:551-560.

40. Zhang Y, Chan DC: Structural basis for recruitment of mitochondrial fission complexes by Fis1. Proc Natl Acad Sci 2007, 104:18526-18530.

41. Gatto GJ, Geisbrecht BV, Gould SJ, Berg JM: Peroxisomal targeting signal-1 recognition by the TPR domains of human PEX5. Nat Struct Biol 2000, 7:1091-1095. 
42. Scheufler C, Brinker A, Bourenkov G, Pegoraro S, Moroder L, Bartunik H, Hartl FU, Moarefi I: Structure of TPR domain-peptide complexes: critical elements in the assembly of the Hsp70-Hsp90 multichaperone machine. Cell 2000, 101:199-210.

43. Zhang M, Windheim M, Roe SM, Peggie M, Cohen P, Prodromou C, Pearl LH: Chaperoned ubiquitylation-crystal structures of the CHIP U box E3 ubiquitin ligase and a CHIPUbc13-Uev1a complex. Mol Cell 2005, 20: 525-538.

44. Pallen MJ, Francis MS, Fütterer K: Tetratricopeptide-like repeats in type-IIIsecretion chaperones and regulators. FEMS Microbiol Lett 2003, 223:53-60

45. Birket SE, Harrington AT, Espina M, Smith ND, Terry CM, Darboe N, Markham AP, Middaugh CR, Picking WL, Picking WD: Preparation and Characterization of Translocator/Chaperone Complexes and Their Component Proteins from Shigella flexneri. Biochemistry 2007, 46:8128-8137.

46. Schoehn G, Di Guilmi AM, Lemaire D, Attree I, Weissenhorn W, Dessen A Oligomerization of type III secretion proteins PopB and PopD precedes pore formation in Pseudomonas. EMBO J 2003, 22:4957-4967.

47. Wang B, Mo ZL, Mao YX, Zou YX, Xiao P, Li J, Yang JY, Ye XH, Leung KY, Zhang PJ: Investigation of EscA as a chaperone for the Edwardsiella tarda type III secretion system putative translocon component EseC. Microbiology 2009, 155:1260-1271.

48. Zheng J, Li N, Tan YP, Sivaraman J, Mok Y, Mo ZL, Leung KY: EscC is a chaperone for the Edwardsiella tarda type III secretion system putative translocon components EseB and EseD. Microbiology 2007, 153:1953-1962.

49. Bogan AA, Thorn KS: Anatomy of hot spots in protein interfaces. J Mol Biol 1998, 280:1-9.

50. Edqvist PJ, Broms JE, Betts HJ, Forsberg A, Pallen MJ, Francis MS: Tetratricopeptide repeats in the type III secretion chaperone, LcrH: their role in substrate binding and secretion. Mol Microbiol 2006, 59:31-44.

51. Francis MS, Lloyd SA, Wolf-Watz H: The type III secretion chaperone LcrH co-operates with YopD to establish a negative, regulatory loop for control of Yop synthesis in Yersinia pseudotuberculosis. Mol Microbiol 2001, 42:1075-1093.

52. Raab R, Swietnicki W: Yersinia pestis YopD 150-287 fragment is partially unfolded in the native state. Protein Expr Purif 2008, 58:53-60.

53. Kabsch W: XDS. Acta Crystallogr D: Biol Crystallogr 2010, 66:125-132.

54. Evans P: Scaling and assessment of data quality. Acta Crystallogr D: Biol Crystallogr 2006, 62:72-82.

55. Collaborative Computational Project N4: The CCP4 suite: programs for protein crystallography. Acta Crystallogr D: Biol Crystallogr 1994, 50:760-763.

56. McCoy AJ, Grosse-Kunstleve RW, Adams PD, Winn MD, Storoni LC, Read RJ: Phaser crystallographic software. J Appl Crystallogr 2007, 40:658-674.

57. Emsley P, Lohkamp B, Scott WG, Cowtan K: Features and development of Coot. Acta Crystallogr D: Biol Crystallogr 2010, 66:486-501.

58. Chen VB, Arendall WB, Headd JJ, Keedy DA, Immormino RM, Kapral GJ, Murray LW, Richardson JS, Richardson DC: MolProbity. Acta Crystallogr D: Biol Crystallogr 2010, 66:12-21.

59. DeLano Warren L: The PyMOL Molecular Graphics System. Schrödinger: LLC; 2011.

60. Baker NA: Electrostatics of nanosystems: Application to microtubules and the ribosome. Proc Natl Acad Sci 2001, 98:10037-10041. a peptide of the minor translocator YopD. BMC Structural Biology 2012 12:13.

\section{Submit your next manuscript to BioMed Central and take full advantage of:}

- Convenient online submission

- Thorough peer review

- No space constraints or color figure charges

- Immediate publication on acceptance

- Inclusion in PubMed, CAS, Scopus and Google Scholar

- Research which is freely available for redistribution 